\title{
Supporting the Supermarket Shopping Experience through a Context-Aware Shopping Trolley
}

\author{
Darren Black \\ Systematic A/S \\ Søren Frichs Vej 39 \\ DK-8000 Århus \\ +4526149144 \\ drdaz7@gmail.com
}

\author{
Nils Jakob Clemmensen \\ Nordjyske Medier \\ Langagervej 1 \\ DK-9220 Aalborg East \\ +4560803457 \\ nc20@nordjyske.dk
}

\author{
Mikael B. Skov \\ Aalborg University \\ Selma Lagerlöfs Vej 300 \\ DK-9220 Aalborg East \\ +4599409940 \\ dubois@cs.aau.dk
}

\begin{abstract}
Shopping in supermarkets is becoming an increasingly interactive experience as stores integrate technologies to support shoppers. While shopping is an essential and routine type of consumer behaviour, emerging technologies posses the qualities to change our behaviour and patterns while shopping. This paper describes CAST - a contextaware shopping trolley designed to support the shopping activity in a supermarket through context-awareness and the acquiring of user attention. The design is based on understandings of supermarket shopping needs and behaviour derived from previous studies. The system supports customers in finding and purchasing products from a shopping list. A field evaluation showed that CAST affected the shopping behaviour and experience in more ways, e.g. more uniform behaviour in terms of product sequence collection, ease of finding products. However, they saved no significant time of the shopping activity.
\end{abstract}

\section{Author Keywords}

Supermarket, shopping, context-awareness, mobile technologies

\section{ACM Classification Keywords}

H5.m. Information interfaces and presentation (e.g., HCI): Miscellaneous.

\section{INTRODUCTION}

Supermarket shopping is an essential and routine type of consumer behaviour (Park et al., 1989) and contemporary shopping is becoming an increasingly interactive experience. Experimental stores like the Metro Groups Future Store integrate several information and communication technologies to as they state, “... create tomorrow's shopping experience ..." (Metro Group, 2009). Also, in several countries, stores are introducing self-checkout points to speed up the paying process, while others integrate barcode scanners where shoppers can get information about products.

Interactive shopping trolleys represent yet another type of emerging technologies in supermarket stores. Manufacturers like Siemens-Nixdorf and MediaCart have started

\footnotetext{
Permission to make digital or hard copies of part or all of this work or personal or classroom use is granted without fee provided that copies are not made or distributed for profit or commercial advantage and that copies bear this notice and the full citation on the first page. To copy otherwise, to republish, to post on servers, or to redistribute to lists, requires prior specific permission and/or a fee.

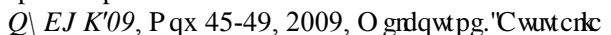

(C) ACM 2009 ISBN: 978-1-60558-400-4/09/10 ...\$10.00
}

to produce shopping trolleys with interactive touch-based screens where customers can find information related to the shopping activity, e.g. the shopping list or information about selected products. With high-speed wireless networks like $3 \mathrm{G}$, people can now access a wide array of information, e.g. cooking recipes or product information, on their mobile devices while shopping and thus, create their own unique shopping experiences. Thus, the future can bring interesting and potentially quite different shopping experiences when applying such interactive trolleys.

Introducing trolley mounted personal interactive touchscreens creates more opportunities and challenges on product promotion. A well-known dilemma in supermarket layout is that product placement influences product exposure and product sale significantly (Larson et al., 2005; Sorensen, 2003). Thus, manufacturers compete for optimised exposure in the stores and include various kinds of campaign ads to support this. However, promoting products and manufacturers on a trolley-mounted display introduce an extra layer of product placement that is still poorly understood and researched.

A fundamental problem for product promotion and exposure on trolley screens is what, when, or where to promote products. E.g. what products should stores show on the display, when should these products be displayed, and where in the store should certain products be displayed? One of the potential promising solutions to such questions could be to integrate context-awareness into the product. Research within context-awareness has focused on the above questions related context where one should consider who, what, where, when, and why questions related the context of the system (Abowd and Mynatt, 2000; Dey et al., 2001). Bohnenberger et al. (2002) utilized context-awareness in a shopping mall guide that could instruct visiting customers which shops to visit. While promising, they also found that the need to constantly attend to the system while navigating the mall was considered a drawback.

In this paper, we describe the design of a prototype for enhancing the shopping experience in supermarkets. The prototype is called CAST (the Context-Aware Shopping Trolley), and it directs customers through a supermarket by outlining product placement in the store and gives additional information about the individual products and similar products within product groups. Elements of context-awareness are used in the solution as attempts to integrate the handling of products with the interaction with the mobile devices (CAST). 


\section{RELATED WORK}

Designing pervasive or ubiquitous technologies for retail and supermarket shopping has received substantial interest from research over the last years as hardware technologies and network infrastructures become more accessible (Roussos and Moussouri, 2004). Supermarkets are ideal environments for exploring technological opportunities as huge numbers of shoppers enter supermarkets every week to select rather few items from several thousands during a short time period (Cumby et al., 2005).

Research studies have focused on different aspects of shopping, but mainly on supporting the shopping activity and experience e.g. shopping mall guidance (Bohnenberger et al., 2002; Kanda et al., 2009), shopping assistants (Cumby et al., 2004, Roussos et al., 2002). Furthermore, some studies focus on related aspects of technology adaptation in supermarkets, e.g. privacy and security concerns (Roussos and Moussouri, 2004). Finally, other studies have investigated supermarket shopping paths or patterns to examine store layout, product placement, and customer behaviour (Girgensohn et al., 2008; Larson et al., 2005), which can be influenced by integrating various pervasive shopping support systems.

Context-awareness provides one interesting perspective on some of the conducted research studies as shoppers often face difficulties in locating items within supermarkets or shopping malls. Previous research has utilized context-awareness in several ways, e.g. the Lancaster GUIDE project (Cheverst et al., 2000) where tourists were guided through the city of Lancaster. Other examples of context-aware systems include electronic patient records (Skov and Høegh, 2006), more general hospital applications (Bardram et al., 2003), museum guides (Lonsdale et al., 2005) and university guides (Griswold et al., 2004).

Kanda et al. (2009) introduce a robot guide in a shopping mall. The robot was designed to interact naturally with the customers and to provide information about shopping and the shopping mall. Field trails showed that 63 out of 235 people changed their shopping behaviour and went shopping based upon the guidance from the robot. Bohnenberger et al. (2002) take a slightly different approach and report from an investigation on a decision-theoretic shopping mall guide. The guide operates at a higher level (macro level) guiding the shopper on which shops to visit in order to make their shopping activity more efficient. The guide achieves this goal using a rather simple interface, which directed the shopper towards shops using arrows. The guide proved both effective and likable according to testing, reducing time spent shopping by a small but significant amount (11\%). However, some of the participants felt that they lacked an overview and were being "led blindfolded" through the shopping mall.

While dealing with context-aware computing and more particular ubiquitous computing, we often need to design technologies that should be objectively visible but subjectively invisible meaning that we should be able to interact with them seamlessly (Chalmers, 2004). For contextaware computing, more research studies have identified challenges for user-computer interaction as interfaces and functionality are updated automatically for context-aware applications causing users to be confused and produce undesirable results (Bohnenberger et al., 2002; Skov and Høegh, 2006; Kjeldskov and Skov, 2007). As such, we find reason to focus our research on how to design a context-aware mobile system that demands user attention, and the effects of such a system in its use-context.

\section{CONTEXT-AWARE SHOPPING TROLLEY (CAST)}

In the following, we outline our context-aware shopping trolley (CAST) solution. First, we describe the motivation for CAST as explained through a field study. Secondly, we illustrate the overall idea behind CAST, and finally, we present the design of CAST.

\section{Contextual Study in Supermarket}

We conducted a contextual study with shoppers in order to understand the shopping activity in supermarkets. The study was based in føtex, Aalborg East, Denmark and this supermarket is part of a chain of medium-sized (by Danish standards) supermarkets. The study consisted of seven shopping sessions, each involving a single shopper, a test leader, and a logger. The test leader conducted in-situ contextual questioning with the shopper, while the logger recorded the shopper's movement around the store.

Seven people were brought into the fotex store and monitored, questioned, and observed while shopping. Five of the seven shoppers were provided with a randomised 29 item-shopping list, while the other two had shopping trips scheduled and thus brought their own lists. The provided list contained a blend of everyday groceries, but also less frequently purchased items to ensure that the participants would cover most areas of the shop floor. Their movement through the store was logged and audio recording captured the interview. Both the logger and the test leader wore audio recording devices to facilitate recording observations. Following the shopping sessions, semistructured interviews were conducted to obtain further contextual and demographic data for analysis. We captured a total of app. 21 hours ( 3 audio tracks, 7 hours each) of audio data along with movement data. The audio tracks for each session were synchronised and the movement data to facilitate analysis of the spoken data in its spatial context.

\section{Observations}

In the following we elaborate on three findings from the study that formed the design of the Context-Aware Shopping Trolley (CAST). More information on this study can be found in (Black and Clemmensen, 2006a, b).

Our first observation showed that our supermarket shoppers often found it difficult to locate and find products. This was expressed in two ways. First, customers sometimes failed to identify products despite being in rather close proximity to the product. This was often caused by either poor product recognition or due to a belief that the product in question was located elsewhere. Secondly, customers often had difficulties in recognizing the products visually. Often they already possessed an assumption on how a product would look like and if this was incorrect or products had changed visual appearance, they 
would face difficulties in finding the products. This observation is illustrated in figure 1 where several of our customers faced difficulties in finding particular wine brands mainly due to the highly identical appearance of all the items.

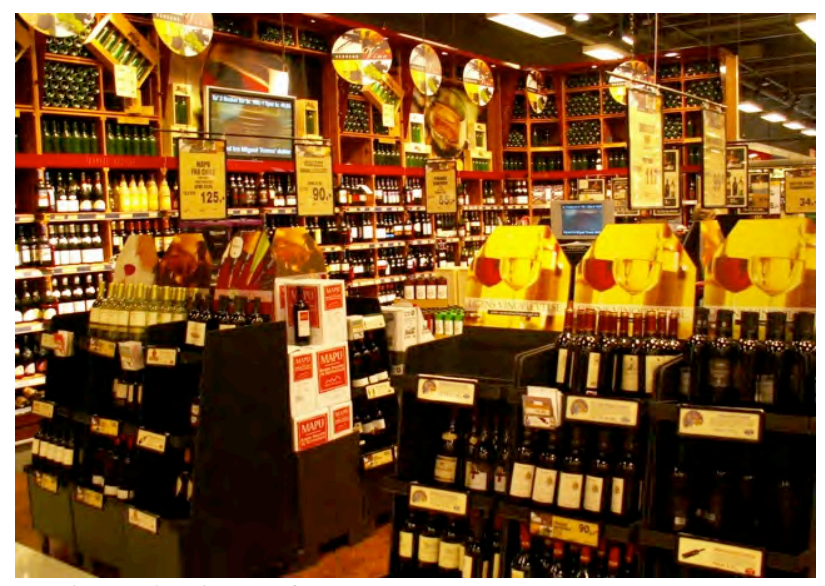

Figure 1: Picture from the supermarket where we conducted contextual interviews.

Our second observation illustrated context complexity. Like many other supermarkets, føtex presents customers with an array of stimuli. Brightly coloured signs, aromas from various products fill areas, and finally music, audio adverts, or announcements played in the store. Also, shelves are crowded with brightly coloured products and packages. All of these sources compete for the customer's attention. In fact, all these stimuli caused problems for the customers every now and then making it difficult for them to efficiently move around the store.

Our third observation illustrated the movement through the store. The physical layout of the store encourages customers to follow a U-shaped route through the store. Customers expressed disdain for any need to 'go back' on the route. Also, our customers stated that a shopping list would always be ordered in some fashion. They were offered the opportunity to re-order the list they were provided, but only one did so. Opinions as to how such a list should be ordered varied - some claimed that it would be by where they thought things were placed in the shop, while others would use a mental model of product groupings to order the list.

Our fourth observation concerned the shopping list organization. All our customers said that their shopping list would always be ordered in some fashion. Opinions as to how such a list should be ordered varied - some claimed that it would be by where they thought things were placed in the shop, while others would use a mental model of product groupings to order the list (the grouping of milk, cheese and eggs was common, for example). In our study, the customers were offered the opportunity to re-order the list they were provided, but only one customer did so.

Our fifth observation concerns product or item collection order. As part of our study, we collected data on product collection order to be able to observe any patterns. For the customers with the pre-defined shopping list, we found no item that was collected at the same time for all five customers. While a number of products showed simi- lar collection patterns, several were quite different in this respect.

\section{Representing Context in Supermarkets}

Our intention with the Context-Aware Shopping Trolley (CAST) was to support the shopping experience by solving or addressing the above-mentioned challenges. Basically, we view these challenges as highly context dependent and as such, a context-aware solution can address or solve some of these challenges (Dey and Barkhuus, 2004).

Based on previous work on context-awareness (Dey et al., 2001; Dourish, 2004; Schmidt et al., 1999; Skov and Høegh, 2006), we define the context of shopping in føtex from following three items:

- Task - the primary task for the customers is to find and collect the items on the shopping list

- Location - the location of the shopper, as well as the locations of products and shelves and the spatial relations between all three.

- Objects - the physical properties and states of products and shelves.

As previously noted, supermarket shopping with a trolley is a multitasking activity that requires visual focus on numerous entities for safe and successful execution. As such, we cannot expect that the user will always have their attention on CAST's graphical user interface, and thus cannot rely on visual updates being noticed. Again, similar conditions are apparent in several documented context-aware systems and have caused various problems. To ensure that the user is aware of CAST's notifications, a different modality was used - aural notification is used to obtain the user's attention. The supermarket is a noisy environment and as such small speakers are unreliable as devices for user notification. To ensure that these notifications are heard, customers are provided with a Bluetooth headset through which all system audio is channelled.

While real-life implementation of CAST would require the use of both positioning sensors and RFID sensors to register product collection, similar to (Buxton, 2007, Paay et al., 2009) we adapted a Wizard-of-Oz strategy for the prototype development of CAST. For this purpose a control centre application was implemented on the .NET Compact Framework 2.0 and deployed on a Pocket PC device. The application consists of two tabbed windows one containing a map of føtex allowing for the updating of the customer's location in CAST, and the other containing the list of products in the system such that the system can be updated when items are collected. In addition the control centre program logs location data and product collection events while maintaining their temporal context, allowing for later analysis. The application uses a standard TCP/IP connection to communicate with CAST (a server side was added to CAST for this purpose), allowing for simplicity in switching between networking technologies. In our testing, Bluetooth was used and proved both stable and responsive. 

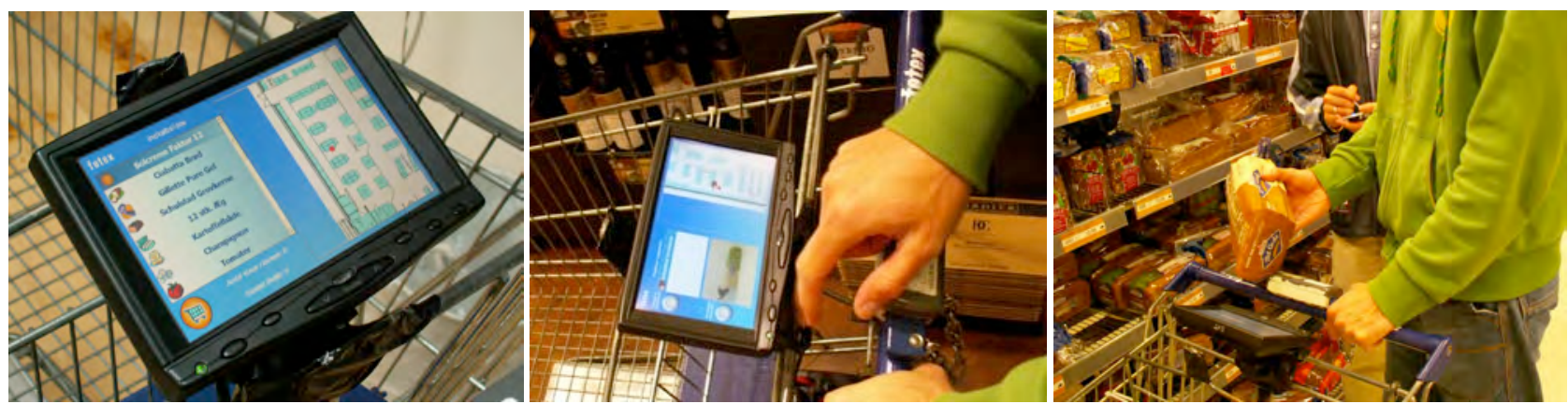

Figure 2: Illustration of CAST in use. The picture on the left illustrates CAST mounted on the shopping trolley with the shopping list on the left hand side of the screen and the map of the store on the right hand side. The middle and left hand side picture illustrates a customer interacting with CAST while locating and selecting groceries.

\section{Interaction Design}

Our solution involves the use of a trolley-mounted, touchsensitive TFT screen (see figure 2). Self-contained devices are available in this format and could be used in a production version of CAST; however the unit used for this prototype is only a touch-sensitive screen - the application runs on a trolley-mounted laptop PC. A trolleymounted battery powers the touch-screen.

The primary aim of CAST is to support shoppers while shopping for groceries and other items in føtex. This is primarily done through the integration of a shopping list. While supermarket shopping involves much more than just collecting shopping list items (Park et al., 1989), we explicitly focused on shopping as an activity where one collects predetermined groceries and other products from a shopping list. Thomas and Garland (1993) found that shopping list customers collect fewer items and spent less money than more causal shopping customers.

CAST supports dynamic ordering of the groceries on the shopping list as a function of what best suits the customer's current context and position in the supermarket (see figure 3). Thus, the shopping list provides a reference point for the customer where he/she can see what needs to be done before their task is considered complete. In order to support the user in this way, the list updates when an item from the list is collected and put into the trolley.

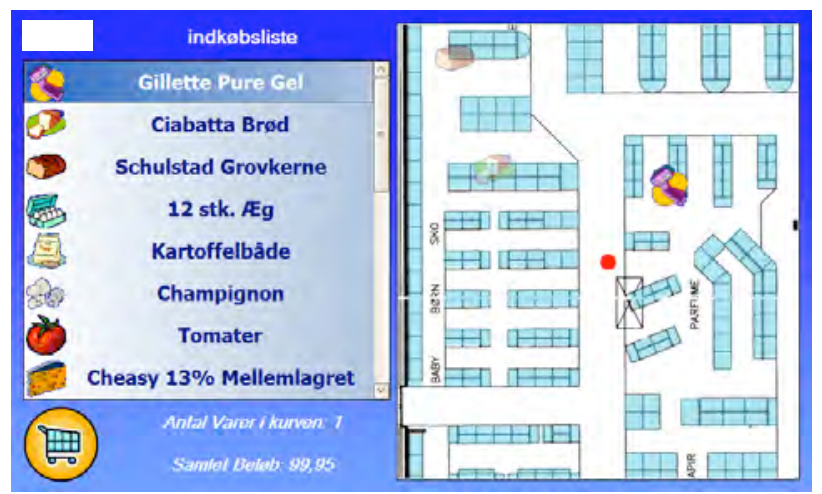

Figure 3: CAST - primary screen with two views: the shopping list (left) and the supermarket with indication of the current position of the customer.

We provide contextual information about the shopper's location through the included map (figure 3, right). The map includes a layout of the entire store and provides information about the current position of the shopper (red dot in figure 3) and the spatial relations to the entire store, the shelves, and items on the shopping list. Our contextaware solution provides location information in several dimensions namely between trolley and shelves, products and shelves, and products and products. In figure 3, three items are shown on the map with their location in the store and a unique icon relates them to the entries in the shopping list. As the shopper moves around, the shopping list reorders itself according to proximity of items. The system informs the shopper of nearby products which are on his/her shopping list by sending an audio alert through the shopper's headset.

Besides giving location information on items in the store, the context-aware shopping trolley provides information on visual appearance of all items (illustrated in figure 4). One of the key challenges identified in our first study was how shoppers would often fail to recognize products from their visual appearance. Thus, all items on the shopping list have a photographic image, which are shown in the interface. Furthermore, the system offers the opportunity to access further information about items and groceries (as illustrated for the eggs in figure 4). Finally, we integrated two levels of product generalisation in the contextaware shopping trolley namely specific products (e.g. Gillette Pure Gel) and product groups (e.g. Shaving Gel). In the event that a product group is entered in the shopping list, all the products in that group are displayed when they are nearby.

\section{EVALUATION}

We designed and conducted a series of evaluation studies to examine the use and applicability of CAST. Similar to other mobile evaluation studies (e.g. Paay et al., 2009), we adapted a Wizard-of-Oz approach where data, e.g. position and product information, were manually entered into the system without subjects' awareness.

While field studies sometimes provide little added value compared to laboratory studies (Kjeldskov et al., 2004), we deliberately chose to conduct the evaluation in a realistic setting as we strived for high realism. Also, as we were interested in the relative effect of CAST on shopping experience, we designed the evaluation to involve two groups of customers namely CAST subjects and traditional shopping list subjects (written on a piece of paper). 


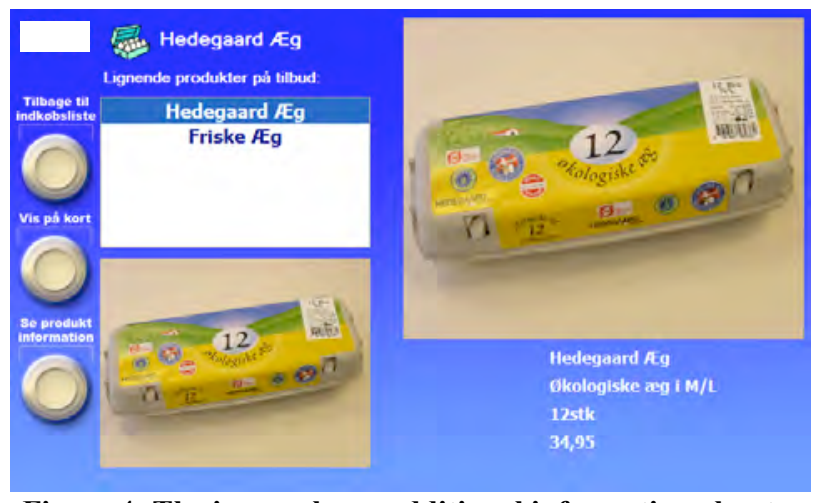

Figure 4: The image shows additional information about a product - in this particular case eggs.

\section{Setting}

The evaluation was carried out in a føtex supermarket (as previously described). føtex is part of a chain of mediumsized (by Danish standards) supermarkets. With a main shopping area of approximately 20.000 square meters this supermarket include a wide assortment of products (food, cosmetics, electronics, clothing and wine).

\section{Participants}

18 subjects (4 females) participated in our evaluation in the age between 24 and 56. The subjects were assigned to one of the two conditions randomly. CAST: 9 subjects ( 8 males and 1 female) ranging from 24-56 years of age $(M=35.11, S D=13.79) .3$ subjects in this group shopped at least once every month in this fotex store while 6 of them rarely or never shopped there. One of the subjects did not own a home computer nor did he use any at work. Shopping List (SL): 9 subjects (6 males and 3 females) ranging from 25-35 years of age $(\mathrm{M}=27.44, \mathrm{SD}=3.57) .4$ subjects in this group shopped at least once every month in this føtex store while 5 of them rarely or never shopped there. One of these subjects did not own a home computer nor did she use any at work.

\section{Procedure}

For the evaluation, we created a shopping list with 23 items daily goods, e.g. milk or bread, as well as normally less frequently purchased products, e.g. sunscreen lotion. All subjects were instructed to envision a scenario where they had been sent shopping for members in their household.

The group using traditional shopping tools were presented with a shopping trolley, the 23 items shopping list and a pen and offered time to examine and rearrange the list if needed. The CAST subjects were briefly introduced to CAST. Both groups would then proceed with their shopping task. In a similar configuration to the field study, a test leader to elicit feedback and a logger to record movement and product collection data accompanied the subjects. Each subject was equipped with an mp3 player to capture audio data from the shopping session. During the sessions, we captured the position of the subject in the supermarket and the product collection order for later analysis.

Following the shopping session the subjects were taken to the supermarket's cafeteria, where they were asked to complete a questionnaire and questions to obtain demo- graphic and other information related to the shopping session.

\section{Data Collection and Analysis}

Multiple means of gathering data were used for both configurations. Audio was captured from small digital mp3 audio recorders worn by the participant and the test leader, and finally the logger continuously captured position and product collection data using a custom made Pocket PC-based logging application. To ease the task of synchronizing data sources ,a marker sound was played back by the logging application when it started logging data. In the CAST sessions, video of the shoppers' interaction with the system was captured by a camera mounted on the trolley. Also, the number of times each participant asked for assistance was recorded.

The logger continuously captured the current position of the subject on a digital map and also marked when products on the list were picked up. These data were automatically written to a file, which contained coordinates and the names of the products that were taken. Both the coordinates and the products were written sequentially and were also marked with a timestamp to allow performance measuring during analysis. During the tests involving CAST this application was also used in a Wizard of Oz fashion (similar to Paay et al., 2009) to simulate the context awareness features of CAST such as location awareness, proximity to products and awareness of trolley contents (this is illustrated in figure 5).

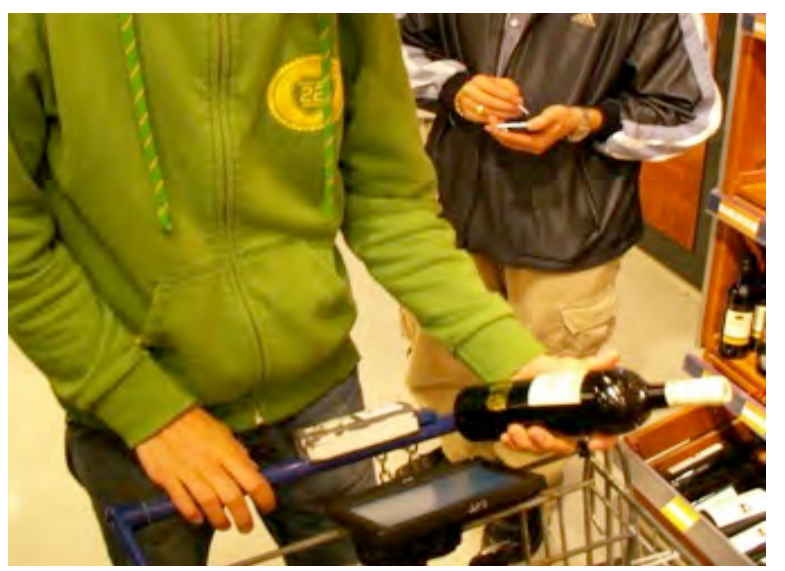

Figure 5: Evaluation trails in the supermarket illustrating a subject choosing an item from the shopping list and the logger behind him recording activity and location.

Having collected all the products, the shopper was given a questionnaire to complete. This questionnaire was designed to provide data related to: demographics, proficiency with technologies such as mobile phones, PDA's, computers and GPS, shopping habits such as how often they brought shopping lists and used trolleys, how easy it was to find products and if they used signage or labels to find products.

In addition to these questions, CAST users had to fill out an extra page containing questions relating to use of the system while shopping for products. The session concluded with a semi-structured interview. We conducted statistical analyses on our data where applicable and used Student's t-test and Chi-square tests. 


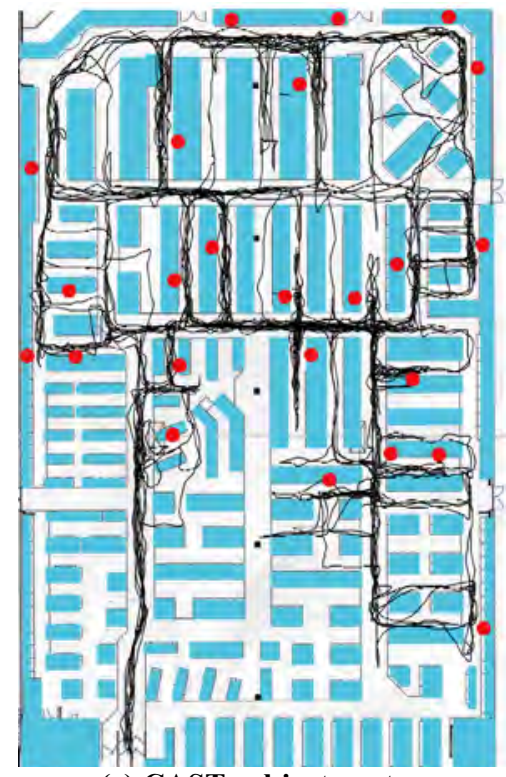

(c) CAST subject routes

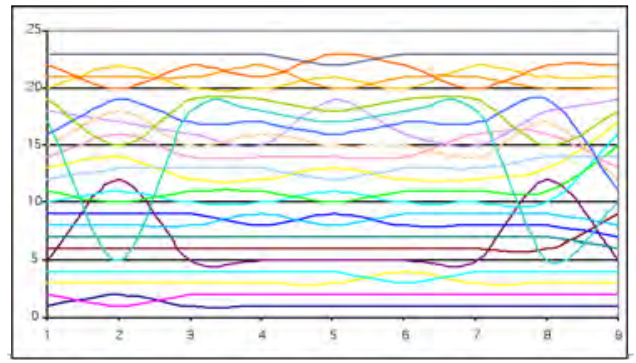

(a) CAST items collection order

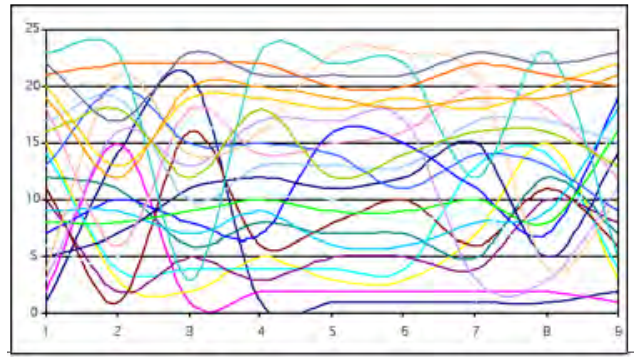

(b) SL items collection order

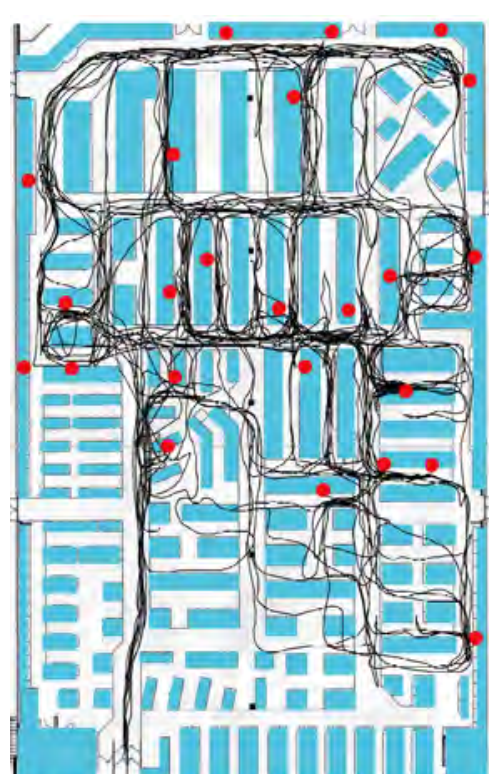

(d) SL subject routes

Figure 6: Shopping items collection order for CAST subjects (a) and shopping list subjects (b). Shopping routes for all nine CAST subjects (c) and all nine SL (shopping list) subjects (d) through the supermarket during the field study. Red dots indicates placement of the 23 items on the shopping list.

\section{FINDINGS}

Our field trails showed that the context-aware solution influenced the shopping activity. First, the items collection orders were quite different between our two groups of subjects where we found that CAST subjects collected products more uniform than the shopping list subjects. This is illustrated in figure $6(\mathrm{a}, \mathrm{b})$ where each line represents one item and the order it was collected for each of the nine subjects in each condition. In fact, the CAST subjects picked up the same product at the same point in the product collection sequence 131 of 207 times compared to 79 of 207 times for the shopping list subjects. A Chi-square test shows this difference to be significant, $\chi^{2}(1)=53.5, \mathrm{p}<.0001$.

The items collection order further indicates that the subjects using our context-aware shopping trolley had a more systematic and guided way of collecting the items on the shopping list. The combined distance travelled during the sessions further exemplifies this. On average, the subjects using the traditional shopping list walked 618.3 meters $(\mathrm{SD}=94.4)$ during the trails while CAST subjects walked 469.1 meters $(\mathrm{SD}=55.5)$. A Student's t-test proves that this difference of 107.4 meters is statistically significant $\mathrm{t}(16)=4.087, \mathrm{p}<0.001$.

The SL subjects backtracked noticeably more than those using CAST. They only backtracked when they had to collect items in a different order to that recommended; they stated that they were aware of the recommendations but felt there were closer items and opted to collect those instead. This is also illustrated in figure $6(\mathrm{c}, \mathrm{d})$ where the paths through the store are depictured for both CAST and shopping list subjects. From the figure, it should also be noticed that CAST subjects mostly stayed in the middle of the aisle while walking around with the shopping trolley - a consequence of the interaction with the system while walking. On the other hand, while walking a longer route through the store for the CAST subjects, we found no major differences for task completion time - CAST $(\mathrm{M}=28: 49, \mathrm{SD}=07: 07)$ compared to traditional shopping list subjects $(M=29: 58, S D=05: 10)$. A Student's t-test confirms no significant difference between the two conditions $\mathrm{t}(16)=0.392, \mathrm{p}=0.70$.

\section{DISCUSSION}

Shopping in supermarket stores is a highly essential and routine type of consumer behaviour (Park et al., 1989) and shopping behaviour and patterns has been of research focus since the 1960's (Farley and Ring, 1966). Our goal with the context-aware shopping trolley was to explore how a context-aware system could influence the shopping experience in supermarkets. Supermarket shopping is already becoming an interactive experience where several stores now integrate self-checkout points to speed up the paying process and manufacturers like Siemens-Nixdorf and MediaCart produce interactive shopping trolleys with touch screens where consumers can find information on e.g. the shopping list or selected products.

Based on field studies, we designed CAST to address a number of consumer challenges when shopping namely difficulties in locating products, high context complexity, and movement through the store. Inspired by previous literature on pervasive computing and context-awareness (Dey et al., 2001; Schmidt et al., 1999), we integrated task, location, and objects in our context-aware shopping trolley solution.

The evaluation illustrated that our consumers benefited from CAST in more ways. They found it easier to locate products - expressed through fewer situations where they asked for help and shorter paths through the store. As a consequence and somewhat surprisingly, the system did not facilitate faster shopping as system interaction caused them to walk slower and often they would completely stop to check e.g. product location or specification. The 
CAST consumers also reported lower mental workload possibly due to fewer problems in locating products.

Displaying products and groceries on a trolley mounted touch screen could potentially affect consumer paths and travelling patterns through the store. CAST did influence the consumers in this way as they had a rather different and more uniform way of collecting items on the shopping list. Supermarket product placement has been found to have a significant influence on product exposure and also sale. Larson et al. (2005) found that products placed at the centre of aisles receive less attention than those placed towards the end, while Sorensen (2003) states that familiar brands at the end of aisles can increase aisles traffic. CAST contributed to such behaviour as our subjects not only navigated from physical context cues in the supermarket, but also from the integrated map in the system. Thus, we saw that CAST consumers never visited several aisles, as these aisles were not represented in the shopping list. Also, shopping list customers often visited aisles not visited by CAST customers, as they had to backtrack several times to collect products.

Knowledge of supermarkets influences shopping behaviour and patterns (Park et al., 1989) and some of our subjects were regular customers in føtex. From our analysis, we found no direct impact on their knowledge when comparing CAST customers. However, several CAST customers stopped using their common sense and instead became highly dependent on the directions given by the system. An observation also found for other contextaware systems, e.g. GPS systems (Saranow, 2008).

Larson et al. (2005) investigated shopping paths from a large data set of 27,000 consumers' paths through a supermarket and they identified 14 canonical paths. They further conclude that "... most shoppers tend only to travel select aisles, and rarely in the systematic up and down pattern most tend to consider the dominant travel pattern ...". Our context-aware trolley solution provided the customers to systematically and thus, they did not have to explore the environment in the same way as ordinary customers have to when visiting a supermarket. As a consequence, the browsing through the store, which was definitely present for the shopping list customers, were almost absent for CAST customers. The inherent focus on the system made them more aware of the touch-screen interface than the physical context. This challenges owners of supermarkets in the design of the environment, e.g. where to place aisles, products, and checkout points.

While we chose to focus on planned shopping with predefined shopping lists, supermarket shopping also involves more causal shopping or impulse shopping with no predefined list (Thomas and Garland, 1993). Iyer (1993) refers to this as scripted versus non-scripted store behaviour. We have no immediate findings on how a context-aware shopping trolley could support non-scripted shopping, but in terms of our understanding of context-awareness, the task would be altered quite significantly in non-scripted shopping. Thomas and Garland (1993) stress that enactment of behaviours in scripted shopping requires fewer environmental cues and reduces effort. This suggests that while our context-aware trolley solution had an impact on shopping behaviour and experience for scripted shopping, the relative effect could possibly be even bigger for nonscripted shopping. However, this raises a number of concerns and challenges on timing and relevance of suggestions made by the system - a problem also identified for a context-aware solution for healthcare domains (Skov and Høegh, 2006).

Some of the key challenges in context-awareness is what, where, when, why, who related to the context and the application (Abowd and Mynatt, 2000). We addressed some of these challenges by integrating a shopping list (utilizing scripted behaviour) and by showing product placement as function of customer placement in the store. Furthermore, we intentionally chose to signal customers through sound when in close proximity of a product on the shopping list. This seemed to have a positive effect of product awareness as CAST customers more easily found and recognized products. Thus, the inherent problem of dynamic updates of context-awareness user interfaces (e.g. Skov and Høegh, 2006) was less a problem for our solution.

\section{CONCLUSION}

Supermarket shopping is already becoming an interactive experience and we designed the context-aware shopping trolley (CAST) to explore the effects on shopping behaviour and experience. Our context-aware solution was evaluated through a number of field trails in a local supermarket where we compared CAST customers with regular shopping list customers when trying to locate and collect the same items. Our findings showed that CAST affected the shopping behaviour and experience in more ways. The CAST customers showed more uniform behaviour in terms of product sequence collection and they also found it easier to find products in the store. On the other hand, several CAST customers stopped using their intuition while shopping and relied heavily on the directions given by the system.

Our research suffers from a number of limitations. First, our study involved an unbalanced number of women and men and this could possibly influence the results of the evaluation. Secondly, shopping is highly private activity taking place in a public context, but the experimental design could possibly affect the findings in the evaluation.

\section{ACKNOWLEDGEMENTS}

We would like to thank the participating subjects in the two evaluations studies and several reviewers on previous versions of the paper. We would also like to thank several anonymous reviewers for valuable comments on previous versions of the paper.

\section{REFERENCES}

Abowd, G. D. and Mynatt, E. D. (2000) Charting Past, Present and Future Re-search in Ubiquitous Computing. ACM Transactions on Computer-Human Interaction, ACM Press, Vol. 7, No. 1, pp. 29-58

Black, D. and Clemmensen, N. J. (2006a) Researching Context-Awareness for Supermarket Application Appendices. Aalborg University 
Black, D. and Clemmensen, N. J. (2006b) When Less is More: Designing for Attention in Mobile ContextAware Computing. Aalborg University

Bardram, J., Kjær, T. A. K., and Nielsen, C. (2003) Supporting Local Mobility in Healthcare by Application Roaming Among Heterogeneous Devices. Proc Mobile HCI 2003, Springer Berlin, pp. 161-176

Bohnenberger, T., Jameson, A., Krüger, A., and Butz, A. (2002) Location-Aware Shopping Assistance: Evaluation of a Decision-Theoretic Approach. Proceedings of International Conference on Human Computer Interaction with Mobile Devices and Services (MobileHCI 2002). Springer Berlin, pp. 18-20

Buxton, B. (2007) Sketching User Experiences: Getting the Design Right and the Right Design. Morgan Kaufmann, San Francisco

Chalmers, M. (2004) A Historical View of Context. Computer Supported Cooperative Work (CSCW) 13(3-4), Springer Netherlands, pp. 223-247

Cheverst, K., Davies, N., Mitchell, K., Friday, A., and Efstratiou C. (2000) Developing a Context-aware Electronic Tourist Guide: Some Issues and Experiences. Proceedings of the Human Factors in Computing Systems (CHI'00), ACM Press, pp. 17-24

Cumby, A., Fano, A., Ghani, R., and Krema, M. (2005) Building Intelligent Shopping Assistants Using Individual Consumer Models. In Proceedings of Intelligent User Interfaces (IUI'05), ACM Press, pp. 323-325

Dey, A.K. and Barkhuus, L. (2003) Is Context-Aware Computing Taking Control away from the User? Three Levels of Interactivity Examined. Proceedings of UbiComp 2003, Springer-Verlag, pp. 149-156

Dey A. K., Abowd G. D., and Salber, D. (2001) A Conceptual Framework and a Toolkit for Supporting the Rapid Prototyping of Context-Aware Applications, Human-Computer Interaction, Vol. 16, No. 2, pp. 97166

Dourish, P. (2004) What We Talk About When We Talk About Context. Personal and Ubiquitous Computing, Vol. 8, No. 1, Springer London, pp. 19-30

Farley, J. U. and Ring, L. W. (1966) A Stochastic Model of Supermarket Traffic Flow. Operational Research. Vol. 14, No. 4, pp. 555-567

Girgensohn, A., Shipman, F., and Wilcox, L. (2008) Determining Activity Patterns in Retail Spaces through Video Analysis. In Proceedings of the 16th ACM International Conference on MultiMedia (MM'08), ACM Press, pp. 889-892

Griswold, W.G., Shanahan, P., Brown, S.W., Boyer, R., Ratto, M., Shapiro, R.B., and Truong, T.M. (2004) Activecampus: Experiments In Community-Oriented Ubiquitous Computing. IEEE Computer, Vol. 37, No. 10, IEEE, pp. 73-81

Iyer, E. S. (1989) Unplanned Purchasing: Knowledge of Shopping Environment and Time Pressure. Journal of Retailing. Vol. 65, pp. 40-57

Kanda, T., Shiomi, M., Miyashita, Z., Ishiguro, H., and Hagita, N. (2009) An Affective Guide Robot in a Shopping Mall. In Proceedings of 4th ACM/IEEE
International Conference on Human-Robot Interaction (HRI'09), ACM Press, pp. 173-180

Kjeldskov, J., Skov, M. B., Als, B. S., and Høegh, R. T. (2004) Is it Worth the Hassle? Exploring the Added Value of Evaluating the Usability of Context-Aware Mobile Systems in the Field. In Proceedings of the 6th International Conference on Human Computer Interaction with Mobile Devices and Services (MobileHCI 2004), Springer-Verlag, LNCS 3160, pp. $61-73$

Kjeldskov, J. and Skov, M. B. (2007) Exploring ContextAwareness for Ubiquitous Computing in the Healthcare Domain. Personal and Ubiquitous Computing, Vol. 11, No. 7, Springer-Verlag, pp. 549-562

Larson, J. S., Bradlow, E. T., and Fader, P. S. (2005) An Exploratory Look at Supermarket Shopping Paths. International Journal of Research in Marketing. Vol. 22, pp. 395-414

Lonsdale, P., Beale, R., and Byrne W. (2005) Using Context Awareness to Enhance Visitor Engagement in a Gallery Space. Proceedings of the HCI05 Conference on People and Computers XIX 2005. pp. 101-112

Metro Group (2009) Metro Group Future Store Initiative www.future-store.org Future Store Rheinberg. Viewed on June 07, 2009

Paay, J., Kjeldskov, J., Howard, S., and Dave, B. (2009) Out on the Town: A Socio-Physical Approach to the Design of a Context-Aware Urban Guide. ACM Transactions on Computer-Human Interaction, Vol. 16, No. 2

Park, C. W., Iyer, E. S., and Smith, D. C. (1989) The Effects of Situational Factors on In-Store Grocery Shopping Behaviour: The Role of Store Environment and Time Available for Shopping. Journal of Consumer Research. Vol. 15, pp. 422- 433

Roussos, G., Koukara, L., Kourouthanasis, P., Giaglis, G., Tuominen, J., Seppala, O., and Frissaer, J. (2002) A Case Study in Pervasive Retail. In Proceedings of the 2nd International Workshop on Mobile Commerce, ACM Press, pp. 90-94

Roussos, G. and Moussouri, T. (2004) Consumer Perceptions of Privacy, Security and Trust in Ubiquitous Commerce. Personal and Ubiquitous Computing, Vol. 8, pp. 416-429

Saranow, J. (2008) Steered Wrong: Drivers Trust GPS Even to a Fault. The Wall Street Journal, March 18, 2008

Schmidt, A., Beigl, M., and Gellersen, H. W. (1999) There Is More To Context Than Location. Computers and Graphics, Vol. 23, No. 6, pp. 893-901

Skov, M. B. and Høegh, R. T. (2006) Supporting Information Access In A Hospital Ward By A ContextAware Mobile Electronic Patient Record. Personal and Ubiquitous Computing, Vol. 10, No. 4, Springer London, 205-214

Sorensen, H. (2003) The Science of Shopping. Marketing Research. Vol. 15, No. 3, pp. 30-35

Thomas, A. and Garland, R. (1993) Supermarket Shopping Lists. International Journal of Retail and Distribution Management. Vol. 21(2), pp. 8-14 